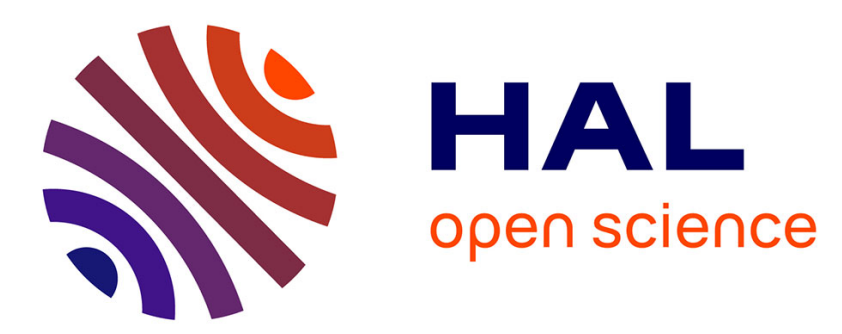

\title{
In situ investigation of liquid films in pulsating heat pipe
} Laura Fourgeaud, Vadim Nikolayev, Eric Ercolani, Jerôme Duplat, Philippe Gully

\section{To cite this version:}

Laura Fourgeaud, Vadim Nikolayev, Eric Ercolani, Jerôme Duplat, Philippe Gully. In situ investigation of liquid films in pulsating heat pipe. Applied Thermal Engineering, 2017, 126, pp.1023 - 1028. 10.1016/j.applthermaleng.2017.01.064 cea-01687377

\section{HAL Id: cea-01687377 https://hal-cea.archives-ouvertes.fr/cea-01687377}

Submitted on 18 Jan 2018

HAL is a multi-disciplinary open access archive for the deposit and dissemination of scientific research documents, whether they are published or not. The documents may come from teaching and research institutions in France or abroad, or from public or private research centers.
L'archive ouverte pluridisciplinaire HAL, est destinée au dépôt et à la diffusion de documents scientifiques de niveau recherche, publiés ou non, émanant des établissements d'enseignement et de recherche français ou étrangers, des laboratoires publics ou privés. 


\title{
In situ investigation of liquid films in pulsating heat pipe
}

\author{
Laura Fourgeaud $^{\mathrm{a}, \mathrm{b}, 1}$, Vadim S. Nikolayev ${ }^{\mathrm{c}, *}$, Eric Ercolani ${ }^{\mathrm{b}}$, Jérôme Duplat ${ }^{\mathrm{b}}$, Philippe Gully ${ }^{\mathrm{b}}$ \\ a PSA, Route de Gisy, 78140 Vélizy-Villacoublay, France \\ ${ }^{\mathrm{b}}$ CEA INAC-SBT, Université Grenoble Alpes, 38000 Grenoble, France \\ ' Service de Physique de l'Etat Condensé, CEA, CNRS, Université Paris-Saclay, CEA Saclay, 91191 Gif-sur-Yvette Cedex, France
}

\section{H I G H L I G H T S}

-3D shape of the liquid film inside PHP is reconstructed from experimental data.

- Existence of a liquid ridge adjacent to the film contact line is shown.

- Both film shape and thickness are explained theoretically.

- Film profile theory agrees with the experiment.

- Theory for the meniscus oscillation dynamics is proposed and compared to experiment.

\section{A R T I C L E I N F O}

Article history:

Received 12 September 2016

Revised 10 January 2017

Accepted 17 January 2017

Available online 19 January 2017

\section{Keywords:}

Pulsating heat pipe

Oscillation

Liquid films

Interferometry

Optical grid deflection technique

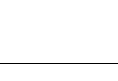

G R A P H I C A L A B S T R A C T

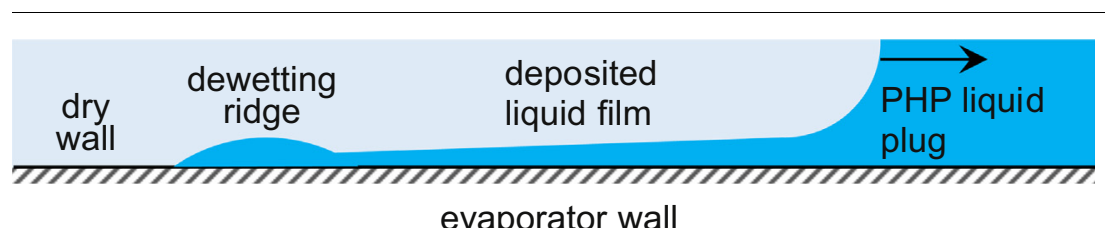

evaporator wall

optical grid deflection technique 


\section{Nomenclature}

A meniscus oscillation amplitude $[\mathrm{m}]$

b singular pressure drop coefficient

$\mathrm{Ca}$ dimensionless capillary number

$D \quad$ spacing between portholes [m]

$f \quad$ oscillation frequency $[\mathrm{Hz}]$

$h \quad$ film thickness [m]

$i \quad$ imaginary unit $=\sqrt{-1}$

$J \quad$ evaporation mass flux $\left[\mathrm{kg} /\left(\mathrm{m}^{2} \cdot \mathrm{s}\right)\right]$

$k \quad$ liquid heat conductivity $[\mathrm{W} /(\mathrm{m} \cdot \mathrm{K})]$

$L \quad$ latent heat $[\mathrm{J} / \mathrm{kg}]$

$l \quad$ characteristic length scale [m]

$L_{r} \quad$ added column height [m]

$p \quad$ vapor pressure [Pa]

$T$ temperature [K]

$t \quad$ time [s]

$U \quad$ velocity $[\mathrm{m} / \mathrm{s}]$

$w \quad$ dewetting ridge width [m]

$x, y \quad$ coordinates $[\mathrm{m}]$

\section{Abbreviations}

$\mathrm{CL} \quad$ contact line

PHP pulsating heat pipe

ITO indium-tin oxide

\section{Greek symbols}

$\Delta T \quad$ internal wall superheating, $T_{w}-T_{\text {sat }}[\mathrm{K}]$

$\mu \quad$ liquid shear viscosity [Pa.s]

$v \quad$ kinematic viscosity $\left[\mathrm{m}^{2} / \mathrm{s}\right]$

$\omega \quad$ angular frequency $\left[\mathrm{s}^{-1}\right]$

$\rho \quad$ liquid density $\left[\mathrm{kg} / \mathrm{m}^{3}\right]$

$\sigma \quad$ surface tension $[\mathrm{N} / \mathrm{m}]$

$\tau \quad$ shear stress [Pa]

$\theta \quad$ interfacial slope, contact angle

\section{Subscripts}

$0 \quad$ right after film deposition

app apparent

$c \quad$ condenser

cl contact line

$i \quad$ initial (at $t=0)$

L liquid

m meniscus

$r \quad$ reservoir

sat saturation

$V \quad$ Voinov

$v \quad$ visible

w internal tube wall exchange, the films are extremely important for the PHP functioning.

In this presentation we concentrate on the film behavior in the evaporator because, for the PHP case, it is more complex than in the condenser where the film thickness grows more or less homogeneously. In the evaporator, the film thinning may lead to its localized drying so that its area changes and the triple liquidvapor-solid contact line (CL) appears. The most important issues for the PHP theory are the film area and thickness. First we consider the film thickness and its evaporation dynamics and next, the $\mathrm{CL}$ effects that turn out to be crucial to understand the film area evolution.

\section{Experimental}

The studies of pure two-phase fluid case in presence of the phase change are much more scarce than in the isothermal case and for the case of different liquid and gas (e.g., water-air), see e.g. [4]. One can mention observations of condensation [5], with application to the LHP condenser. The film evaporation studies are more important for the PHP case where the partial evaporator drying occurs frequently. To our knowledge, the first film observation has been made in the U-turn (two branch) water PHP [6]. Several film observations have been carried out since then [7-9]. The film length has been measured in the single branch PHP [8]. The film profile direct measurements in the capillaries of the circular section are very difficult. For instance, it is impossible to use the confocal microscopy [9] in the cylindrical tubes, although such a method was successful for the capillary HP case. The film profile reconstruction based on the measurements of the spatial temperature distribution with the infra-red camera lacks precision either [10]. It is possible to know only the film length by this method [11].

For the present experiment, we have chosen the twodimensional capillary, i.e. that of rectangular cross-section with the high aspect ratio, $2 \times 22 \mathrm{~mm}^{2}$. The experiments are carried out with simplest, single branch PHP. It is a vertical capillary of about $83 \mathrm{~cm}$ total length sealed from one (top) end (Fig. 1a). Its bottom end is open to a large closed two-phase reservoir regulated at a constant vapor pressure $p_{r}$. Since the films in different bubbles are independent in the multibranch PHP, such a film study is quite general. The working fluid is the pure ethanol. A special care is taken to extract all the impurities in situ with a special purifying device so that the saturation pressure corresponds to its reference value. The middle part of capillary is the condenser maintained at a constant temperature $T_{c}<T_{r} \equiv T_{s a t}\left(p_{r}\right)$ with a thermal bath. The upper part of capillary is the evaporator formed by two transparent sapphire portholes (Fig. 1b) fixed on a copper structure. ITO (indium-tin oxide) layers are deposited at each porthole (outside). They are heated independently with electric current. The evaporator is separated from the condenser by $1 \mathrm{~cm}$ high adiabatic section, made with a thermally insulating material

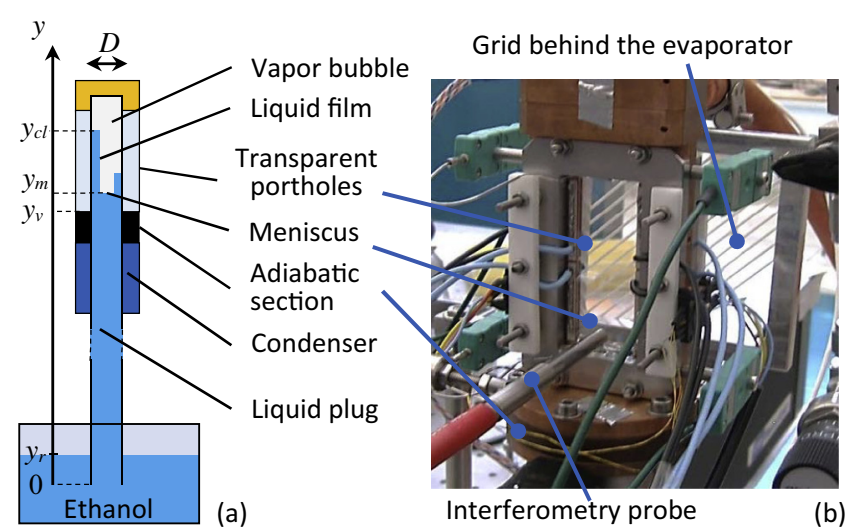

Fig. 1. (a) Sidewise scheme of the whole PHP and (b) a zoom of the PHP upper part (front view of evaporator and adiabatic section). The setup is backlit with the diffuse light and is filmed by a camera from the front. 
$\left(\right.$ Vespel $\left.^{\circledR}\right)$. The internal cross-section of different capillary parts is matched with a high precision to avoid as much as possible the CL pinning at their junctions. Two thermocouples are glued externally at the top and at the bottom of each porthole to measure their temperatures. The vapor pressure $p$ is measured by the fast response pressure transducer located at the top of the evaporator. The evaporator is filmed with a video camera. The portholes are heated with the transparent ITO layers. A much higher power is applied to the rear porthole so that the film on it disappears quickly and the front film can be studied alone.

The meniscus is brought into the evaporator by lowering $T_{c}$ (which leads to $p$ decrease). The liquid meniscus can vertically oscillate around its equilibrium position. These oscillations become self-sustained when an imposed axial thermal gradient causes periodic evaporation and condensation of the fluid [12]. When the meniscus recedes from its topmost position ( $t=0$ in Fig. 2), the films are deposited at each porthole, their evaporation starts because $T_{w}>T_{\text {sat }}$ and $p$ rises. When the meniscus attains a part of the tube where $T_{w}<T_{s a t}$, the film condensation occurs at the lower film part [12]. In addition, the vapor expands. Both these effects cause a $p$ decrease in spite of the continuing evaporation from the upper film part. When the pressure drops low enough, the meniscus begins to rise under the action of the pressure difference $p_{r}-p$. Because of the liquid column inertia, the meniscus rises back into the evaporator and the next oscillation occurs.

\section{Theoretical reconstruction of the meniscus oscillation}

The meniscus equation of motion corresponds to that derived for the meniscus oscillations in the open capillary [13] augmented with the viscous friction term:

$\rho\left(y_{m}+L_{r}\right) \dot{U}_{m}=-\rho g\left(y_{m}-y_{r}\right)+p_{r}-p-\frac{1}{2} \rho U_{m}^{2}+\frac{1}{2} b \rho U_{m}^{2}-\frac{2}{D} \tau y_{m}$,

where $L_{r}$ is the effective length of the liquid in the reservoir that participates in the oscillations, dot means the time derivative, $U_{m}=\dot{y}_{m}$, and $y=0$ corresponds to the bottom of the tube (Fig. 1a). The singular pressure losses coefficient

$b= \begin{cases}-\frac{1}{2}, & \text { if } U_{m}>0, \\ 0, & \text { if } U_{m} \leqslant 0\end{cases}$

corresponds to a hole in a wall because the tube wall thickness is much larger than $D=2 \mathrm{~mm}$.

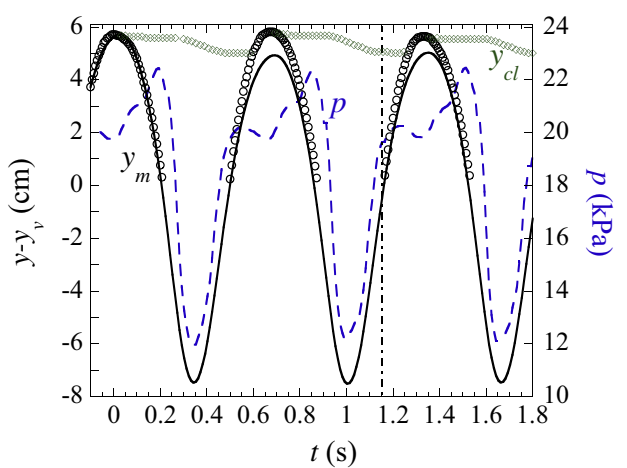

Fig. 2. Time evolution of the vapor pressure (dashed line), meniscus position (circles) and the topmost CL point in the evaporator measured for $p_{r}=23.7 \mathrm{kPa}$, $T_{c}=0{ }^{\circ} \mathrm{C}$, and heating powers $4 \mathrm{~W}$ and $60 \mathrm{~W}$ at the front and rear portholes (Fig. 1b), respectively; $f=1.5 \mathrm{~Hz}$. The height $y_{v}=68 \mathrm{~cm}$ corresponds to the bottom of visible fluid (Fig. 1a). The reconstructed theoretically meniscus oscillation is shown with the solid line.
The viscous shear stress is defined mainly by the bulk flow, the meniscus effects being negligible for long liquid plugs [14]. One uses usually the Poiseuille expression, $\tau=6 U_{m} \mu / D$. However the oscillatory flow does impact the dissipation. The shear stress is defined in this case by the expression [15]

$\tilde{\tau}=-\widetilde{U}_{m} \mu \chi \tanh \left(\frac{D \chi}{2}\right)\left[\frac{2 \tanh \left(\frac{D \chi}{2}\right)}{D \chi}-1\right]^{-1}$,

written in the Fourier space, with $\chi=\sqrt{i \omega / v}$, tilde denoting the Fourier-transformed variables. One mentions that Eq. (2) reduces to the Poiseuille expression in the limit $\omega t_{\text {visc }} \rightarrow 0$, where $t_{v i s c}=D^{2} /(4 v)$ is the characteristic viscous relaxation time. In our case, Eq. (2) results in about 1.5 times larger dissipation value than its Poiseuille counterpart.

Since all the parameters in Eq. (1) are known, $y_{m}(t)$ evolution can be reconstructed now by using $p(t)$ measured experimentally (Fig. 2). For the reconstruction, $L_{r}=15 \mathrm{~cm}$ and the ethanol parameters for $T=35^{\circ} \mathrm{C}$ are used ( $\left.\rho=777 \mathrm{~kg} / \mathrm{m}^{3}, \mu=0.9 \cdot 10^{-3} \mathrm{~Pa} \cdot \mathrm{s}\right)$. By comparing with the part of the curves measured in the transparent evaporator part, one concludes that the reconstruction quality is reasonably good.

\section{Film thickness}

One can distinguish several regions in the evaporator (Fig. 3). First of all, these are liquid plug, dry wall and liquid film regions. The liquid film appears because of its deposition of the receding meniscus (the Landau-Levich phenomenon). The film thickness is controlled by the balance between the viscous friction force that prevents the liquid from flowing along the solid and surface tension in the meniscus region that tends to keep all the fluid inside the plug $[16,17]$. The thickness of the film deposited by the receding with the velocity $U_{m}$ meniscus in a capillary of the diameter $D$,

$h_{0}=0.67 D C a_{m}^{2 / 3}$

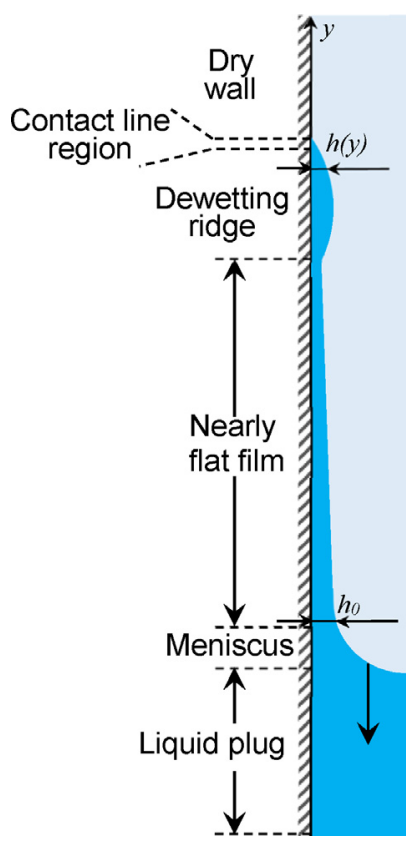

Fig. 3. Different regions appearing during the liquid plug receding over a hot wall (in the PHP evaporator) 
is defined by the capillary number $C a_{m}=\mu U_{m} / \sigma$. The Taylor bubble films have been extensively studied experimentally in isothermal situation. The expression (3) has been corrected to account for many secondary effects like liquid inertia but still remains applicable. In our experiment, the film thickness has been measured by interferometry at a fixed height similarly to [18], by using the Ocean Optics HR2000+ spectrometer. The white light is sent perpendicularly to the film surface by the apparatus probe and the reflected light is recovered by the same probe (Fig. 1). The rays reflected from both film interfaces (with the solid and with the vapor) interfere, which creates multiple maxima in the light spectrum measured by apparatus. The local film thickness is directly deduced from the wavelengths corresponding to the maxima. The thickness measured during the same run at different probe heights (that correspond to different $U_{m}$ ) is presented as a function of $C a_{m}$ in Fig. 4. One can see that the measurements are coherent with Eq. (3).

\section{Slope of the drying film}

Under isothermal situation, the deposited film remains flat. The reason for this is that the film is immobile in the wall reference while the liquid flow occurs only at two film ends: in the region where the film is connected to the meniscus and near the dried out solid wall portion (Fig. 3). The film profile is not perturbed by the gravity either: the film thickness is much smaller than the capillary length, which is usually millimetric. However the liquid film thickness may vary because of evaporation [10]. To account for this effect, one can neglecting the flow along the film so that the film thickness $h(y, t)$ changes because of evaporation only:

$\dot{h}=-\frac{J}{\rho}$.

The film that has stayed longer after its deposition by the receding meniscus becomes thinner so at a given time moment the film should be thicker near the meniscus and thinner far from it. To obtain the film shape, consider the energy balance at the film surface. It is always at $T_{\text {sat }}$ corresponding to the vapor pressure (perhaps, except at the areas where the evaporation is so strong that molecular kinetic effects become important) because the fluid is pure. By neglecting the heat flux leaving the surface for the vapor with respect to the latent heat, one can write the energy balance as $[19,20]$

$J=\frac{k \Delta T}{h L}$

and use it in Eq. (4). By assuming invariable $\Delta T$ in the evaporator section (due to its high heat conductivity), one gets the solution of Eq. (4),

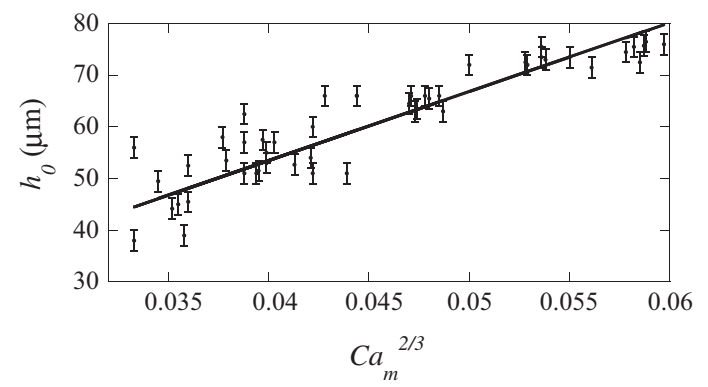

Fig. 4. Film thickness measured by interferometry (characters) just after the film deposition at different heights to obtain different meniscus velocities. It is compared to Eq. (3) (line) $h(y, t)=\sqrt{h_{0}^{2}-2 \frac{k \Delta T}{L \rho}\left(t-t_{0}\right)}$,

where $t_{0}<t$ is the time moment of the meniscus passage through the point $y ; h_{0}=h\left(t=t_{0}\right)$ is the thickness given by Eq. (3), which depends on $U_{m}=U_{m}\left(t_{0}\right)$. The variables $y$ and $t_{0}$ are related through $y=y_{m}\left(t_{0}\right)$ where $y_{m}(t)$ is the meniscus motion law. For the slope calculation, one can approximate the actual meniscus trajectory with the harmonic oscillation

$y_{m}=y_{i}+A[\cos (\omega t)-1]$,

where $y_{i}=y_{m}(t=0)$. One obtains

$t_{0}=\frac{1}{\omega} \arccos \left(\frac{y-y_{i}}{A}+1\right)$,

to be used in Eq. (6).

The film thickness evolution calculated with Eq. (6) is compared to that measured at several fixed heights after the film deposition in Fig. 5. This figure describes the nearly flat film portion schematized in Fig. 3. It is indeed nearly flat: its experimental slope of $0.6^{\circ}$ (Fig. 5b) is well reproduced by the theoretical curve (Fig. 5a).

Both theory and experiment presented in this section have their limitations: they are not capable to resolve the dewetting ridge schematized in Fig. 3. The interferometry measurements are limited because of large interface slopes. To overcome this limitation, the grid deflection technique will be applied below. To describe the dewetting ridge theoretically, the CL effects need to be considered.

\section{Contact line effects}

It is known since long ago [21] that evaporation causes the apparent contact angle increase. In the liquid wedge geometry characteristic for the CL region (Fig. 3), such an effect is explained by the strong evaporation (cf. Eq. (5)) in the vicinity of the CL where $h(y) \rightarrow 0$ when $y \rightarrow y_{c l}$. The theory of this phenomenon has been developed by a number of researchers, see e.g. [22-26], and is summarized here very briefly. A liquid mass loss localized in the microscopic vicinity of the CL requires a liquid flow towards it, which creates the viscous pressure drop along $y$, i.e. the pressure $p_{L}$ in the liquid decreases with $y$. Since the vapor pressure is homogeneous, both the interfacial pressure jump $p-p_{L}(y)$ and the local interface curvature defined through the Laplace equation increase with $y$, which leads to the interface slope decrease with $y$. As the

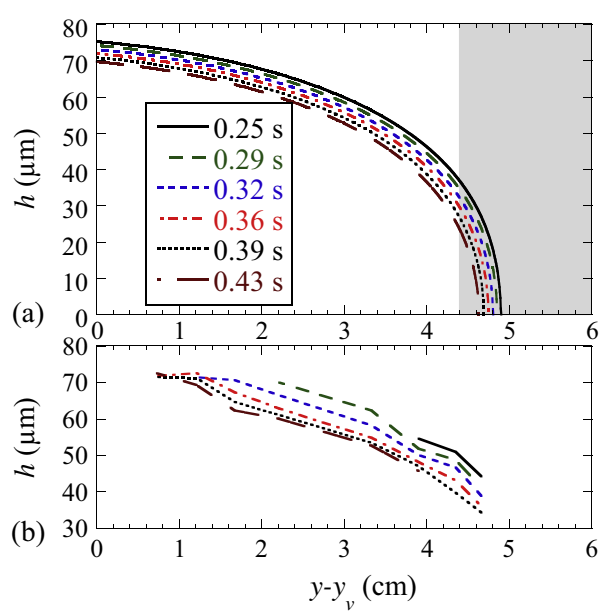

Fig. 5. Film thinning caused by evaporation: (a) calculated with $A=6 \mathrm{~cm}, \Delta T=10^{\circ}$ and the meniscus curvature radius of $0.8 \mathrm{~mm}$ to conform to $h_{0}$ value obtained with the interferometry measurements (b). The region influenced by the CL effects is shadowed in (a). 
interface slope at the CL $\theta$ is fixed by the intermolecular forces, the slope $\theta_{V}$ at some microscopic distance from the CL depends on evaporation rate and may attain a large value $\theta_{V} \gg \theta$. The $\theta_{V}$ value increases with $\Delta T$ and depends weakly on a microscopic length scale $l_{V} \simeq 100 \mathrm{~nm}$ defined in practice by the hydrodynamic slip length divided by the interface slope. The vapor recoil effect [27] also contributes to the $\theta_{V}$ increase. Note that the Voinov angle can be seen as an effective contact angle caused by the substrate superheating.

If the CL was immobile, this angle could be measured in a hypothetic setup where the interface shape is not imposed by the macroscopic constraints. In reality, the CL moves and one needs to account for the related flow and slope change. It turns out that in the presence of the CL motion the apparent contact angle (i.e. that obtained by extrapolation of the macroscopic shape toward the $\mathrm{CL}$ ) is expressed by the Cox-Voinov-type expression [26]

$\theta_{a p p}^{3}=\theta_{V}^{3}+9 C a_{c l} \ln \frac{w}{e l_{V}}$,

where $e \simeq 2.71, \mathrm{Ca}_{c l}=\mu U_{c l} / \sigma$ and $w$ is a relevant macroscopic scale (dewetting ridge width in the present case [28]).

One knows that the liquid film is unstable when the solid surface is not wetted. Once a CL is formed, it recedes spontaneously. The liquid gathered by receding cannot flow inside the thin film because of the strong shear. For this reason it is accumulated in a "dewetting" ridge [29] formed along the film edge. When the ridge is small, its shape is controlled by the surface tension; its crosssection should be circular.

It is quite important to note that since the ridge shape is circular, $\theta_{a p p}$ and $w$ are related to each other once the ridge volume is given. As the ridge accumulates the fluid, its volume is defined by $U_{c l}$. One obtains finally that $U_{c l}$ is defined only by $\theta_{V}[29,30]$. Within a logarithmic prefactor calculated in [28], $C a_{c l} \sim \theta_{V}^{3} / 9$.

One can now analyze the experimental data to find the described above phenomena experimentally.

\section{Film shape reconstruction}

A non-intrusive, optical grid deflection technique [30-32] has been used to capture the film shape in situ, during the PHP functioning. A wire grid (formed by parallel wires) is placed between the diffuse light source and the cell, cf. Fig. $1 \mathrm{~b}$. The wire direction is inclined to $45^{\circ}$ to avoid it to be parallel to the CL. The incident light rays are refracted at the inclined film interface. The local film slope can be deduced from distortion of the grid image (Fig. 6a). A local $\mathrm{h}$ measurement is needed to reconstruct its spatial variation
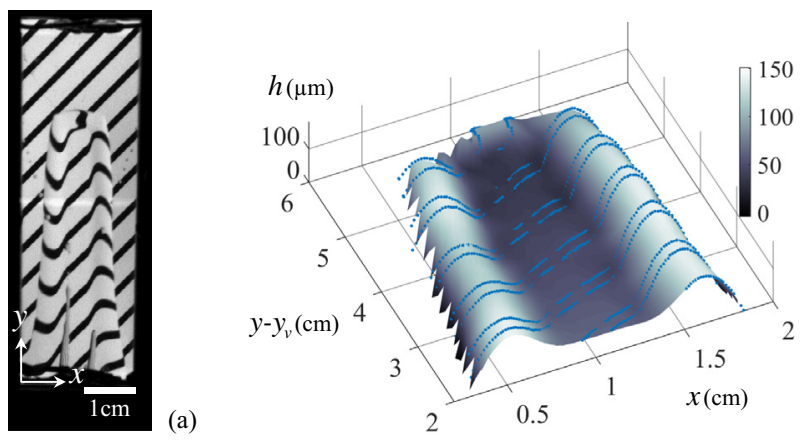

Fig. 6. Raw image (a) and the corresponding 3D reconstruction of the film profile (b). The surface is obtained by interpolation between reconstructed points (characters) along the images of grid edges. Note that the lateral ridge parts appear because of the rectangular tube and heating mode; they are absent in the circular tube PHP. along the single wire image; the discussed above interferometry data have been used for this purpose.

An obtained image and corresponding to it reconstruction of the film shape are shown in (Figs. 6). The time moment corresponding to the image is shown by the vertical dash-dotted line in Fig. 2 . The central film portion is obtained from the interferometry measurements, while the dewetting ridge shape is calculated using the grid deflection analysis.

To obtain the apparent contact angle one needs to cut the 3D fit of the film surface by $y=$ const plane. The fits show that the dewetting ridges are indeed circular, in agreement with the above theory. Since the experimental data are impossible to obtain very close to the contact line, one needs to use the fits to determine $\theta_{a p p}$.

From $\theta_{\text {app }}$ and $U_{c l}$, the contact angle can be calculated with Eq. (9). Note that $U_{c l}<0$ and $\theta_{V}>\theta_{a p p}$. In the present experiment, $\theta_{V}$ can reach $30^{\circ}$ [33].

\section{Discussion and conclusions}

One can understand now the CL dynamics (Fig. 2). Since the thermal inertia of the sapphire portholes is high, one can reasonably assume that the temperature variation of their internal surfaces is small so that the $\Delta T$ variation is inverse of that of $p$. Let us remind that $\theta_{V}$ is the increasing function of $\Delta T$. At $t=0, p$ is high $\left(\theta_{V}\right.$ is low) so that $\mathrm{CL}$ is pinned on surface defects. The $p$ drop leads to a sharp $\theta_{V}$ increase so that the dewetting starts: CL recedes. Once $p$ rises again, $\theta_{V}$ drops and becomes pinned again. The meniscus washes up the film, brings CL to the upper position and the oscillation starts again.

One can see that because of the contact angle increase appearing due to intensive evaporation in a microscopically small region, a thicker ridge forms at the film edge. This locally decreases the film evaporation so that the film edge receding dynamics is defined rather by dewetting effect than by the overall film evaporation as assumed in the state-of-the-art PHP simulations [34]. The physics of the $C L$ receding is understood. The CL velocity is defined mainly by the so called Voinov contact angle that is defined mainly by the superheating of internal PHP walls.

The discovered film shape contradicts previous ideas $[8,10]$ about the wedge-like films in the PHP. In reality, the film is nearly flat (which conforms to the hypothesis made in 1D PHP simulations [34]) with a ridge at its end.

Because the films inside the bubbles of conventional, multibranch PHP evolve independently of each other, the findings obtained here for the single branch PHP apply for the multibranch case. The particularity of the flat geometry is the trapezoidal film shape, which is absent in the circular cross-section tubes. However the capillary ridge and, more generally, film dynamics observed here holds in the general case. Since the film area is one of the key factors influencing the PHP dynamics, these findings are very important to be implemented in the future both single and multi-branch PHP simulations.

\section{Acknowledgments}

The financial contributions of PSA Peugeot-Citroën, of ANR in the framework of the project AARDECO ANR-12-VPTT-005-02, of CNES within the "Fundamental and applied microgravity" program and of European Space Agency within MAP INWIP are acknowledged.

This work is a part of the PhD thesis of L. Fourgeaud [35].

\section{References}

[1] H. Akachi, Structure of micro-heat pipe, US Patent 5219020, 1993. <https:// www.lens.org/lens/patent/US_4921041_A>. 
[2] Y. Zhang, A. Faghri, Advances and unsolved issues in pulsating heat pipes, Heat Transfer Eng. 29 (1) (2008) 20-44, http://dx.doi.org/10.1080/ 01457630701677114.

[3] S. Khandekar, P.K. Panigrahi, F. Lefèvre, J. Bonjour, Local hydrodynamics of flow in a pulsating heat pipe: a review, Front. Heat Pipes 1 (2) (2010) 023003. http://dx.doi.org/10.5098/fhp.v1.2.3003.

[4] A. Tripathi, S. Khandekar, P.K. Panigrahi, Oscillatory contact line motion inside capillaries, in: Proc. 15th Int. Heat Pipe Conf., Clemson University, Clemson, USA, 2010.

[5] B. Médéric, P. Lavieille, M. Miscevic, Heat transfer analysis according to condensation flow structures in a minichannel, Exp. Therm Fluid Sci. 30 (8) (2006) 785-793, http://dx.doi.org/10.1016/j.expthermflusci.2006.03.008.

[6] G. Lagubeau, Propulsion par moteur pop-pop, Master's thesis, supervisor: D. Quéré, PMMH-ESPCI, Paris, 2006.

[7] T. Hao, X. Ma, Z. Lan, N. Li, Y. Zhao, H. Ma, Effects of hydrophilic surface on heat transfer performance and oscillating motion for an oscillating heat pipe, Int. J. Heat Mass Transfer 72 (2014) 50-65, http://dx.doi.org/10.1016/j. ijheatmasstransfer.2014.01.007.

[8] M. Rao, F. Lefèvre, S. Khandekar, J. Bonjour, Heat and mass transfer mechanisms of a self-sustained thermally driven oscillating liquid-vapour meniscus, Int. J. Heat Mass Transfer 86 (2015) 519-530, http://dx.doi.org/ 10.1016/j.ijheatmasstransfer.2015.03.015.

[9] V. Srinivasan, V. Marty-Jourjon, S. Khandekar, F. Lefèvre, J. Bonjour, Evaporation of an isolated liquid plug moving inside a capillary tube, Int. J. Heat Mass Transfer 89 (2015) 176-185, http://dx.doi.org/10.1016/j. ijheatmasstransfer.2015.05.039.

[10] N. Chauris, V. Ayel, Y. Bertin, C. Romestant, Evaporation of a liquid film deposited on a capillary heated tube: experimental analysis by infrared thermography of its thermal footprint, Int. J. Heat Mass Transfer 86 (2015) 492-507, http://dx.doi.org/10.1016/j.ijheatmasstransfer.2015.03.013.

[11] S. Fischer, T. Gambaryan-Roisman, P. Stephan, On the development of a thin evaporating liquid film at a receding liquid/vapour-interface, Int. J. Heat Mass Transfer $88 \quad$ (2015) 346-356, http://dx.doi.org/10.1016/j. ijheatmasstransfer.2015.04.055.

[12] V.S. Nikolayev, Effect of tube heat conduction on the single branch pulsating heat pipe start-up, Int. J. Heat Mass Transfer 95 (2016) 477-487, http://dx.doi. org/10.1016/j.ijheatmasstransfer.2015.12.016.

[13] E. Lorenceau, D. Quéré, J.-Y. Ollitrault, C. Clanet, Gravitational oscillations of a liquid column in a pipe, Phys. Fluids 14 (6) (2002) 1985-1992, http://dx.doi. org/10.1063/1.1476670.

[14] M.T. Kreutzer, F. Kapteijn, J.A. Moulijn, C.R. Kleijn, J.J. Heiszwolf, Inertial and interfacial effects on pressure drop of Taylor flow in capillaries, AlChE J. 51 (9) (2005) 2428-2440, http://dx.doi.org/10.1002/aic.10495.

[15] R. Panton, Incompressible Flow, third ed., Wiley, New York, 1996, ISBN: 9780471593584.

[16] F.P. Bretherton, The motion of long bubbles in tubes, J. Fluid Mech. 10 (1961) 166-188, http://dx.doi.org/10.1017/S0022112061000160.

[17] L.D. Landau, B.V. Levich, Dragging of a liquid by a moving plate, Acta Phys.Chim. USSR 17 (1942) 42-54, http://dx.doi.org/10.1016/B978-0-08-0925233.50016-2.
[18] J.H. Snoeijer, J. Ziegler, B. Andreotti, M. Fermigier, J. Eggers, Thick films of viscous fluid coating a plate withdrawn from a liquid reservoir, Phys. Rev. Lett. 100 (2008) 244502, http://dx.doi.org/10.1103/PhysRevLett.100.244502.

[19] V.S. Nikolayev, Dynamics of the triple contact line on a nonisothermal heater at partial wetting, Phys. Fluids 22 (8) (2010) 082105, http://dx.doi.org/ $10.1063 / 1.3483558$

[20] V. Nikolayev, S.K. Sundararaj, Oscillating Menisci and liquid films at evaporation/condensation, in: Proc. 17th Int. Heat Pipe Conf., Begell, 2015, pp. 59-68, ISBN: 978-1-56700-453-3.

[21] M. Potash, P.C. Wayner, Evaporation from a two-dimensional extended meniscus, Int. J. Heat Mass Transfer 15 (10) (1972) 1851-1863, http://dx.doi. org/10.1016/0017-9310(72)90058-0.

[22] L.M. Hocking, On contact angles in evaporating liquids, Phys. Fluids 7 (1995) 2950-2955, http://dx.doi.org/10.1063/1.868672.

[23] S. Moosman, G.M. Homsy, Evaporating menisci of wetting fluids, J. Colloid Interface Sci. 73 (1) (1980) 212-223, http://dx.doi.org/10.1016/0021-9797(80) 90138-1.

[24] S.J.S. Morris, Contact angles for evaporating liquids predicted and compared with existing experiments, J. Fluid Mech. 432 (2001) 1-30, http://dx.doi.org/ $10.1017 /$ S0022112000003074.

[25] V. Janeček, V.S. Nikolayev, Contact line singularity at partial wetting during evaporation driven by substrate heating, Europhys. Lett. 100 (1) (2012) 14003 , http://dx.doi.org/10.1209/0295-5075/100/14003.

[26] V. Janeček, B. Andreotti, D. Pražák, T. Bárta, V.S. Nikolayev, Moving contact line of a volatile fluid, Phys. Rev. E 88 (2013) 060404, http://dx.doi.org/10.1103/ PhysRevE.88.060404.

[27] V.S. Nikolayev, D.A. Beysens, Boiling crisis and non-equilibrium drying transition, Europhys. Lett. 47 (3) (1999) 345-351, http://dx.doi.org/10.1209/ epl/i1999-00395-x.

[28] J.H. Snoeijer, J. Eggers, Asymptotic analysis of the dewetting rim, Phys. Rev. E 82 (2010) 056314, http://dx.doi.org/10.1103/PhysRevE.82.056314.

[29] P.-G. de Gennes, F. Brochard-Wyart, D. Quéré, Capillarity and Wetting Phenomena: Drops, Bubbles, Pearls, Waves, Springer, New York, 2004.

[30] J.H. Snoeijer, G. Delon, M. Fermigier, B. Andreotti, Avoided critical behavior in dynamically forced wetting, Phys. Rev. Lett. 96 (2006) 174504, http://dx.doi. org/10.1103/PhysRevLett.96.174504.

[31] V. Gurfein, D. Beysens, Y. Garrabos, B.L. Neindre, Simple grid technique to measure refractive index gradients, Opt. Commun. 85 (2-3) (1991) 147-152, http://dx.doi.org/10.1016/0030-4018(91)90384-P.

[32] J. Hegseth, A Oprisan, Y. Garrabos, V.S. Nikolayev, C. Lecoutre-Chabot, D. Beysens, Wetting film dynamics during evaporation under weightlessness in a near-critical fluid, Phys. Rev. E 72 (2005) 031602, http://dx.doi.org/10.1103/ PhysRevE.72.031602.

[33] L. Fourgeaud, E. Ercolani, J. Duplat, P. Gully, V.S. Nikolayev, Evaporation-driven dewetting of a liquid film, Phys. Rev. Fluids 1 (2016) 041901, http://dx.doi.org/ 10.1103/PhysRevFluids.1.041901.

[34] V.S. Nikolayev, A dynamic film model of the pulsating heat pipe, J. Heat Transfer 133 (8) (2011) 081504, http://dx.doi.org/10.1115/1.4003759.

[35] L. Fourgeaud, Analyse de la dynamique du film liquide dans un caloduc oscillant Ph.D. thesis, Université Grenoble Alpes, 2016. https://tel.archivesouvertes.fr/tel-01409530. 